\title{
Towards the Definition, Implementation and Communication of an IT Strategy: the Case of IT Strategy at EPFL
}

\author{
Gorica Tapandjieva ${ }^{1}$, Didier Rey Marchetti ${ }^{1}$, Irina Rychkova ${ }^{2}$, Alain \\ Wegmann $^{1}$ \\ 1 École Polytechnique Fédérale de Lausanne, \\ Systemic Modeling Laboratory LAMS \\ Station 14, CH-1015 Lausanne, Switzerland \\ \{gorica.tapandjieva, didier.rey, alain.wegmann\}@epfl.ch, \\ WWW home page: http://www.epfl.ch \\ 2 Centre de Recherches en Informatique, Paris 1 \\ 90 rue Tolbiac, C.14.05, 75013 Paris, France \\ irina.rychkova@univ-paris1.fr, \\ WWW home page: http://www.univ-paris1.fr/
}

\begin{abstract}
Large enterprises need to coordinate the IT initiatives that exist in different organisational units of the enterprise. If these initiatives are not coordinated, the resulting IT system is likely to become difficult to use and expensive to develop/maintain. Enterprise architecture methods are designed for that purpose. We report on the use of a service-oriented enterprise architecture method, called SEAM, in the context of a mid-size university. The originality of SEAM is its service orientation and the recursive modeling from business down to systems. Using SEAM, we develop a service model of the overall organisation. The model is stored in a web-based tool. We also propose a concrete implementation of architectural principles described in the literature. This principles help build an integrated IT system. The paper explains the background of this project and the current progresses. This approach illustrates how enterprises can build a common view for their IT resources.
\end{abstract}

Key words: enterprise architecture, services, business and IT alignment, SEAM, Solu-QIQ

\section{Introduction}

Today organisations rely on information technology (IT) as a support for their business goals, regardless of the services and products they provide. Business and IT alignment play a vital role in an organisation's success. IT provides business value, so the IT strategy should be carefully developed together with the business strategy.

All the work presented here is based on a case study. The case study is the enterprise architecture (EA) of the École Polytechnique Fédérale de Lausanne 
(EPFL). On the main campus there are over 11,000 people including students, researchers and staff. The work of all these people is supported by IT systems. Some of these IT systems are designed for all of the people on campus, some are used only by students and professors, and some are used only by the administrative staff.

In general, IT strategy includes multiples aspects spanning from technology selection to business process structure. In this project we are focusing mostly on how to best structure the relations between the business processes and the IT services, through the implementation of the architecture principles proposed by Ross, Weill and Robertson [6].

Our goal is to illustrate our proposed IT strategy. We present the goals and the plan of actions through working on this case study at EPFL. First, in Section 2, we focus on understanding the challenges. Then, in Section 3, we list the initiatives at EPFL that currently address these challenges. In Section 4, we present the basic elements that construct the IT strategy based on EA principles [6], and we suggest a way of communicating the IT strategy within the organisation. For this communication we use the Solu-QIQ tool, based on the methodology of urbanisation of IT systems (URBA), and the systemic enterprise architecture methodology (SEAM). In Section 5, we illustrate the application of our suggestions on a specific example of the business process, the process of hiring new Ph.D. students. We finish with the overall conclusions and future work.

\section{Main Challenges}

EPFL is a large organisation (with over 4500 employees) and it faces many IT challenges. For example, currently at EPFL there are around 100 different systems (both business and infrastructure) that provide services to EPFL's community. They can be grouped in several categories. Some of these systems are listed in Table 1.

The table shows systems managed by the Central Services. In addition to these systems, each laboratory within an institute or a school, has its own resources. The data about IT systems at EPFL is gathered by EPFL's information system's coordinator, Didier Rey. From this data, we see that all of the resources involved in the operation, maintenance and development of IT systems are highly distributed.

Additionally, new emergent technologies regularly appear. When used, they can cause changes in the current landscape of systems. In terms of resources, the situation becomes more complicated. The number of new IT projects continuously increases, as well as the time required to complete them. A major challenge is to manage even the new projects with the current resources. Some of these resources are the most basic ones: electricity and cooling.

Furthermore, EPFL is a complex system that has an impact by delivering services that support its three core missions: education, research and technology 
Table 1. Some of the IT systems at EPFL, grouped in several categories

\begin{tabular}{|r|l|}
\hline \multicolumn{2}{|c|}{ Mission: } \\
\hline IS-Academia & $\begin{array}{l}\text { Academic management tool used by students, lecturers, re- } \\
\text { searchers, administrative staff, etc. } \\
\text { Infoscience } \\
\text { Matabase used to archive and report works and scientific publica- } \\
\text { tions. } \\
\text { Learning management system and course sharing platform used } \\
\text { as course support. } \\
\text { Portal for uploading and following research and scientific equip- } \\
\text { ments requests at EPFL }\end{array}$ \\
\hline GrantsBD Administration: \\
\hline SA-Academia & $\begin{array}{l}\text { Finances and human resources management system } \\
\text { The same academic management tool can be used for room book- } \\
\text { ing, courses and exams schedule, grades management, etc. } \\
\text { Sharepoint }\end{array}$ \\
\hline Content and document management system \\
\hline Active Directory
\end{tabular}

transfer. To ensure the quality of service (QoS), EPFL must protect its boundaries and be efficient inside this boundary. We can achieve this efficiency by optimizing the business processes and the resources used.

Indeed, the current IT systems work well. The greatest challenge appears when business processes need to be integrated across organisational units. We see integration as a problem, because people and IT systems involved in business processes are typically not in one organisational unit. When people and IT systems are in separate units, it is difficult for them to work together and communicate.

EPFL has already made efforts to address all these challenges. These efforts are explained in the following section.

\section{Current Initiatives}

At EPFL exists an information systems coordination body (Coordination des systmes d'information - CSIN) that has the mission of aligning the development of IT systems with EPFL's strategy and of assuring the coordination between different IT units. This body has several committees, commissions and management groups. CoordAppl - Coordination des applications is one of them.

CSIN organised several workshops at EPFL with target to:

- define high-level strategy by reviewing the impact of the applications on the return of investments (Gartner, early 2012) 
- define the set of principles on how to select a project by giving specific axioms (2011)

- provide project management training (Hermes training, 2011)

- build a prototype to evaluate the integration of IT systems, by using the open source enterprise service bus (WSO2 ESB) [11], a part of a master's thesis project.

- propose a service-oriented approach to a help desk (ITIL transition workshop at DIT, in progress)

- identify gaps in the existing processes and find solutions for them (CoordAppl SEAM workshop on Ph.D Hiring, 2012 - present)

The conclusions from these workshops apply only to their specific problems and do not offer long-term solutions for the overall IT landscape. We propose an approach that offers a durable solution for the organisation of IT systems at EPFL. The concrete example upon which we elaborate our work is based on the progress and outcome of the ongoing CoordAppl SEAM workshop. In this workshop, we work with people responsible for the main IT systems and the heads of certain IT departments at EPFL. The combination of their knowledge, expertise and experience helps us to identify problems and solutions.

In most of the workshops, we use SEAM [10, 9, 7], a family of methods for strategic thinking, business / IT alignment, and requirements engineering. We use SEAM to communicate about the organisation and the IT systems. Furthermore, SEAM conceptualizes different aspects of an organisation: its business, enterprise architecture and software development. Also, it shows different organisational-level hierarchies, and it enables designers to choose how to see the system: as a whole (a black box), or as a composite (a white box). In addition, SEAM shows the behaviours of the systems, the properties representing the information exchanged, and the actors participating in the process. The originality of SEAM is in the integration of generic system thinking principles into discipline-specific methods. [8]

\section{Basic Elements of the Proposed IT Strategy}

In the aforementioned workshops, we address the gaps inside business processes themselves and the gaps between business processes and IT. We followed Ross's, Weill's and Robertson's [6] recommendations of using architectural principles. These architectural principles "provide a rallying point for managers responsible for building out and exploiting the enterprise architecture" [6], which consists of the following:

1. Core business processes

2. Shared data driving core processes

3. Key linking and automation technologies

4. Key customers

The IT strategy we implement is our interpretation of these architectural principles. We explain: 
1. Core business processes - For each core business process, there has to be someone who takes care of the user's needs, who knows every detail of the process, its rules and regulations. This person should be able to design the process and know how to change it when the business strategy changes. This is the role of a process owner [4].

2. Shared data driving core processes - Data is an essential asset of every organisation. Its integrity, quality, security and utility are the most important features. The person responsible for the data used and exchanged in a business process is the data steward [3].

3. Key linking and automation technologies - Our key concept is service. We base our understanding of a service on a definition from systems thinking, [2] "The service concept represents a unit of essential functionality that a system exposes to its environment"; where a system, "is a group of interacting, interrelated, and interdependent components that form a complex and unified whole". Based on the given definition, the key linking and automation technologies represent the connection of IT systems (done by a middleware) and the connection of services supporting processes. From this, the people (and systems) who participate in providing one service or process should belong to one (virtual) unit.

4. Key customers - As many people are involved in the business process, it is very important to identify the key actors.

In Section 2, we have seen the challenges EPFL faces. In this section, we propose a solution that requires changes in EPFL's enterprise architecture, which involves identifying a process owner, a data steward, key customers and a linking technology around the services. The change would not take place all at once, especially not when a large number of people and systems are involved. Educating people about this proposed strategy is an important part of a successful change. By learning about it, people can better accept the change. Once they see that their individual goals are aligned with the business goals and they observe their contribution to the strategy, the process of educating them should be an easy task. Therefore, applying the architectural principles in EPFL's IT strategy requires two actions:

1. Create a service-oriented enterprise architecture (EA) based on the architectural principles presented.

At EPFL, there are over 50 separate ongoing projects that are part of the current IT strategy. Having synergy among these projects would improve the overall IT strategy. We use our interpretation of the architectural principles to achieve this synergy. As an enterprise is a complex system, its main characteristic is continuous evolution [9]. We manage this evolution by using SEAM representation of the architectural principles. In the various SEAM models, an enterprise's evolution and the changes we propose are easily reflected. We use SEAM because it is systematic and it is recursive from business down to technology. In a traceable manner SEAM explicitly shows the services provided and the processes that implement these services. Moreover, SEAM 
models service systems allowing to modify the organizational boundaries. All SEAM models are made with the SeamCAD tool.

2. Create a shared vision of the service architecture by communicating about this vision with everyone involved.

We use, together with SEAM, another EA approach: the urbanisation of IT systems (URBA). URBA is a methodology used mainly in France. We apply URBA's suggestion only for using a cartography tool. For this, we chose Solu-QIQ [1], a tool successfully used by many companies (including RATP [5]). The tool offers an iterative approach for building a cartography of the information systems. As an output, the tool automatically generates a navigational web site that we use to communicate with people involved in building the systems. The advantages of Solu-QIQ over other tools is that it can be used for massive modelling and that the meta-model in the background makes it fully customisable. This customisation allows Solu-QIQ to support SEAM, so we use it as a database to store our SEAM models.

\section{Illustrating the IT Strategy: Example}

IT strategy is a very broad field. When many systems are involved, as is the case with EPFL, the IT strategy has several dimensions. This is the reason we focus only on specific parts and domains of EPFL's business. The IT strategy we suggest can be applied, however, to all domains and functionalities. We show the work we did on one business process; it can serve as an example for working on other processes.

In this section, the spotlight is on the process of hiring a new doctoral (Ph.D.) student. As mentioned before, this process is used in the CoordAppl workshop. We use a SEAM model to better perceive the anomalies and problems in the process.

This process is useful for evaluation because is a common process at EPFL. From the Ph.D. hiring process, we learned which services and sub-processes can be also used in post-doc and professor hiring processes. Moreover, the problems (encountered by the actors in the process) demonstrate the need for integration of systems, alignment of IT with business process, and alignment of processes with business strategy.

In Subsection 5.1, we describe the flow of specific actions in the process. In Subsection 5.2, we identify the specific problems. This is followed by the SEAM representation of the as-is and the to-be models, shown in Subsection 5.3. In Subsection 5.4, we illustrate the basic functionalities of the Solu-QIQ cartography tool. In addition, we present an example of the service view. This view is important for communicating with people about our service-oriented EA vision of the IT strategy. We complete the section with suggestions on how to apply the IT strategy based on the lessons learned from working on this example. 


\subsection{Description of the Ph.D. Hiring Process}

\section{Inscription:}

The process begins when an applicant fills an application record on IS-Academia (Table 1). Record validation is possible only if three reference letters are completed on IS-Academia directly by the applicant's references. Afterwards the doctoral program committee (including the doctoral program assistant) analyses all application records and decides who is admissible to the program. The doctoral program assistant informs the applicants about this decision by e-mail. The doctoral program assistant also informs the lab professors by e-mail.

\section{Selection:}

After having identified potential (admitted) applicants, the professor organises interviews (with or without the help of the lab's administrative assistant). After the interviews, matches are made with one professor and one student interested in working together. This part of the process is not supported by any existing system. IS-Academia is used only to insert some notes about candidates the professors are interested in, and of course, for reading the candidate's data from the application record.

\section{Employment:}

The professor informs the lab's administrative assistant of his decision, and this assistant asks the doctoral program assistant to prepare an admission letter that confirms the hiring of the selected candidate by the professor's lab. This letter has to be signed by the doctoral program director and the professor hiring the candidate. This is the key step in the actual hiring of the Ph.D. student. The lab administrative assistant, asks the future students for the usual required documents (CV, passport copy, etc.). These documents, together with the admission letter are sent to the $H R$ assistant, who is responsible for making the contract and arranging for visa, if needed. Once the contract is ready, it is sent for signature to the future Ph.D. student and a new record in SAP is made for him. From this point on, the employment record of the Ph.D. student is in SAP, and his academic record is in IS-Academia.

\subsection{Ph.D. Hiring Process: Problems}

We identify, together with the CoordAppl workshop participants, most of the problems. These problems have two facets. The first facet shows the difficulties actors are facing. These actors are those directly involved in the process (professor, applicant, i.e., future Ph.D. student, doctoral school administrative assistant, HR assistant, etc.). Some of the problems are:

- Physical documents get lost during the process.

- The same data from the future Ph.D. student's record is inserted by different people in two separate systems: IS-Academia and SAP.

- Confidential data is easily accessible.

- After the applicant has been selected, he is not aware of the status of the process, so he cannot know when something goes wrong. 
- Getting the hard copy of the contract is critical for a future Ph.D. student. He needs it to apply for housing and permit, if needed. Also, he must be officially enrolled in the doctoral program to benefit from free language courses.

The second facet shows the business and technical reasons these problems are difficult to solve:

- Different administrative procedures and rules in EPFL's 18 doctoral programs.

- No document management system connected with IS-Academia and SAP.

- Low level of coordination between the people involved in the separate units.

- Not integration between IS-Academia and SAP, leading to redundancy and duplication of data and documents.

- No person responsible for the business process, someone who knows the rules in depth and is able to make decisions (business process owner). The same applies to the data (data steward).

\subsection{Systemic Enterprise Architecture Methodology (SEAM)}

We use the SeamCAD tool to build the SEAM models that conceptualizes the business process. Fig. 1 shows the as-is model of the Ph.D hiring process. We do not show the details about the execution of the process and the documents exchanged. What can be seen is the separate organisational units that provide services and participate in the process. The problems identified are caused by lack of integration between these units.

The solution to this example problem is depicted on Fig. 2. Everyone providing services to the process is put in one virtual integrated unit. The SEAM representation of being in one container (called working object) means that everyone shares resources and is aware of what is going on inside. A + sign on an object represents what is added by the solution, and a $\sim$ sign represents what needs to be changed. Now, in the to-be model we have the following:

- a virtual Ph.D. hiring service unit is added, which groups everything involved in providing services to the Ph.D. hiring process;

- an additional role of a business process owner is attributed to the EDOC deputy dean;

- a data steward is added;

- an enterprise service bus (ESB) is added that links processes and services from different systems in the virtual Ph.D. hiring service unit;

- all the heads of the current organisational units are now added to the management of the integrated process.

Fig. 2 shows the service organisation of the Ph.D. hiring process. The only remaining challenge is moving people from the as-is to the to-be, hence we use the cartography tool. 


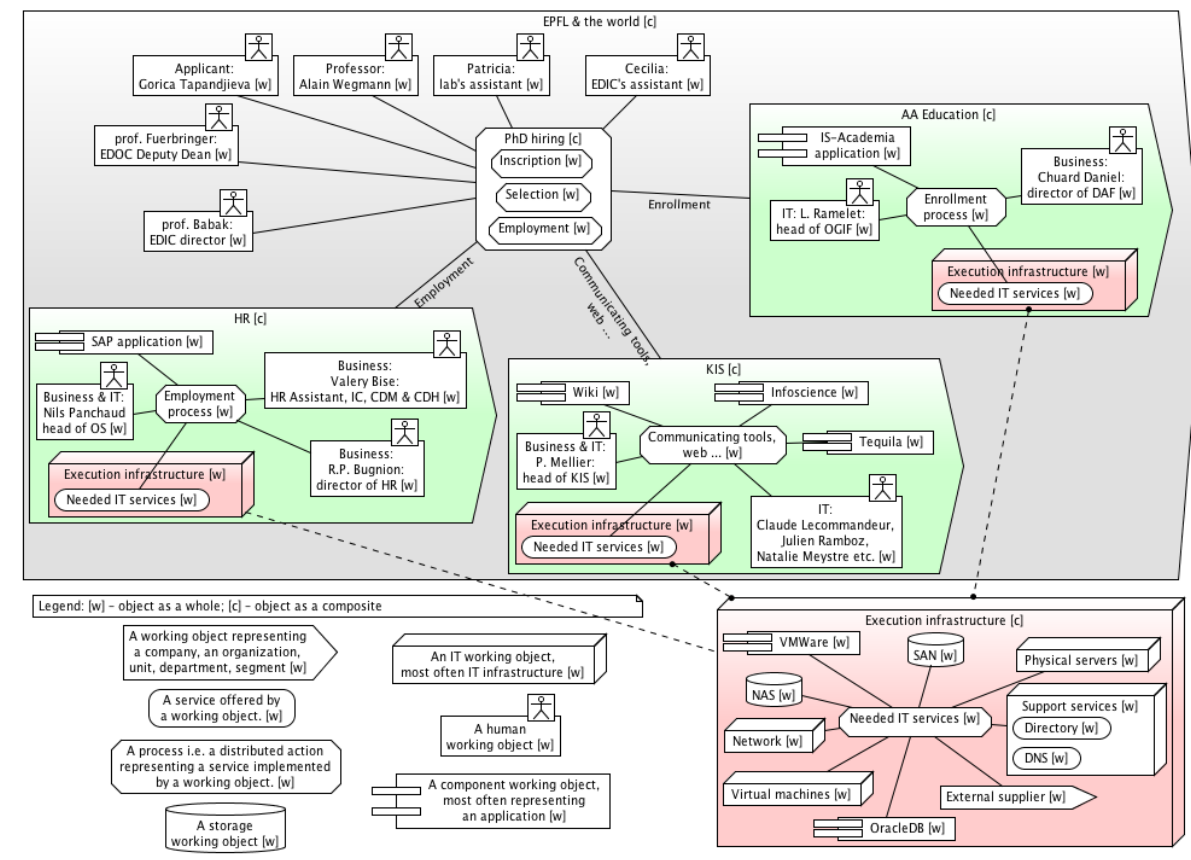

Fig. 1. SEAM as-is model of the Ph.D. hiring process. The separate organisational units can be seen.

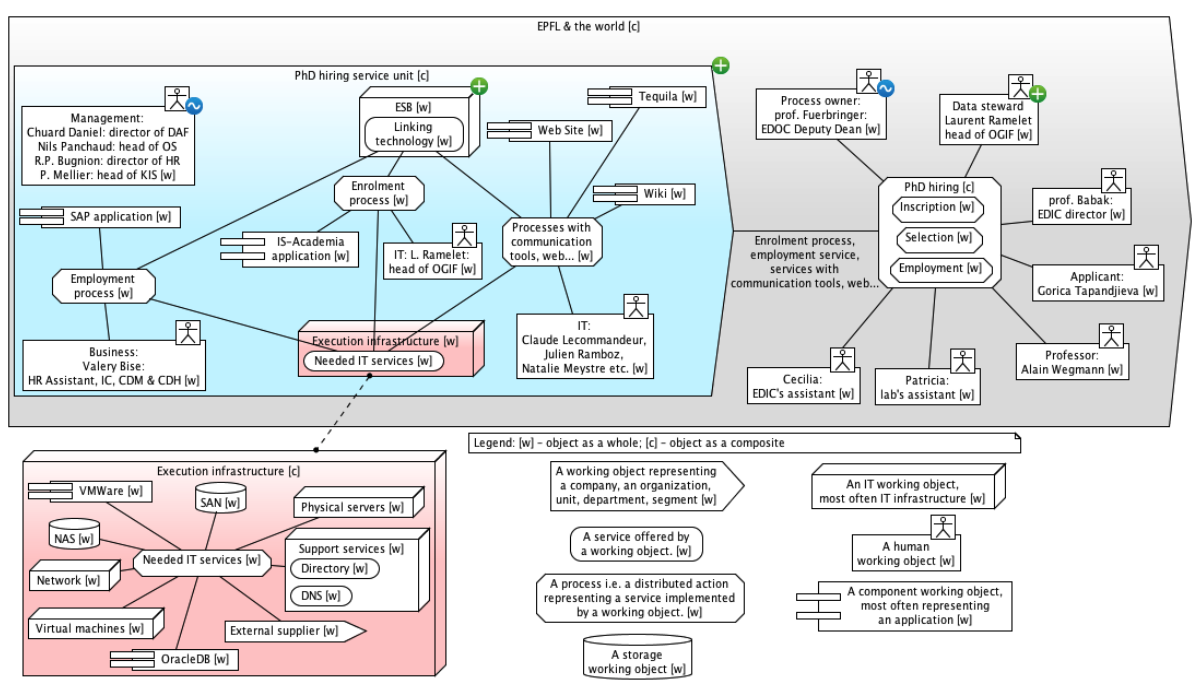

Fig. 2. SEAM to-be model of the Ph.D. hiring process. The virtual service unit integrating people and systems from several organisational units can be seen.

\subsection{Solu-QIQ - Urbanisation of IT Systems (URBA)}

The Solu-QIQ [1] cartography tool outputs a navigation web site which makes our IT strategy easily accessible and transparent. The first step is to define a 
meta model, the graphical representation of organisation's structure, showing the four basic urbanisation views: business, functional, application and infrastructure. In our meta model we additionally have a service view and an organisational view.

The meta model is only a database schema, so data has to be inserted into the tool in order to get an output. Data gathering requires interviewing involved people (business-process actors, department heads, IT specialists, etc.).

In order to ensure that the views of the participants have been correctly captured, additional in-depth interviews are necessary. Subsequently, the output is regenerated and rechecked. An example output ${ }^{1}$ of the tool can be seen in Fig. 3. It shows a concrete example of a SEAM model: the IT systems (IS-Academia and Moodle) and actors (Alain Wegmann and Didier Rey) that provide a service (Recuperation des fichiers), projects related to this service (GED and Support évolution...), and the process in which the service is involved (Sélection des candidat-e-s).

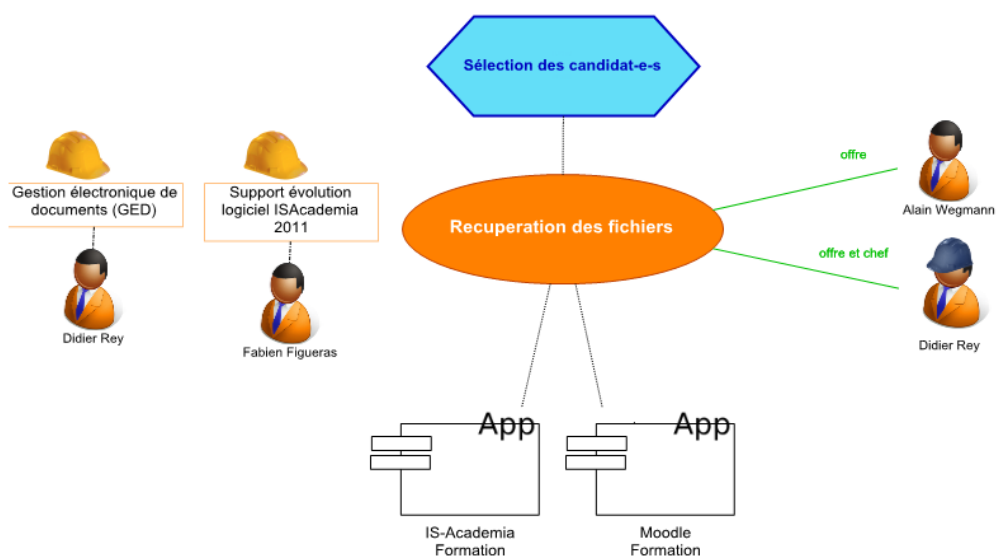

Fig. 3. One output of the web site that the Solu-QIQ tool generates, showing the applications and actors providing a service, projects around this service, and the process that consumes that service

\subsection{Suggestions}

From the Ph.D. hiring example, we are able to provide guidelines and describe the future work for employing the IT strategy. Here are our suggestions:

1. Construct the SEAM as-is model following a pattern based on the example shown here. Communicate with all people involved in providing a service by

\footnotetext{
${ }^{1}$ All of the work connected with the cartography and the Solu-QIQ tool is done as a master's thesis project by a LAMS student.
} 
using Solu-QIQ's output. Through interviews, all of these people contribute to making the cartography of the IT systems. This way, they see all the people and all the IT systems involved in providing the same service. If the output does not show their view of the service, they have the power to react (during the interviews) and even modify the shape of the cartography. After several iterations of interviews, the cartography output will converge to one common view. This is the most accurate view of the EA. Then, we can construct the SEAM to-be model, identify the process owner and the data steward. For the linking technology, once an appropriate middleware is found, it can be used for other business processes too. With these actions we suggest what to do.

2. Reorganise the organisational units into one virtual unit based on the services they provide (one unit per service). We recommend service-orientation in the whole enterprise, captured by SEAM usage. After the cartography is completed, actors can continue communicating by using SEAM models. This set of actions explain why we do what we do.

3. Obtain relevant information about certain IT systems (their use and interaction) by working on one functionality at a time. We work only on the processes that belong to that functionality. After the models have converged, we choose another business process belonging to that same functionality. This action explains how we plan to work across whole EPFL.

4. This work is currently done by a research lab (LAMS) acting as consultant, but later it will be performed by someone within the governance organization (CSIN). Appropriate person needs yet to be identified, so only in the future we can specify who will do the work.

\section{Conclusions}

In this paper, we first present the main challenges that EPFL faces with designing an IT strategy and the initiatives currently taken to overcome them. Then we address EPFL's enterprise architecture, according to our proposed IT strategy and our interpretation of the architectural principles. These architectural principles require that a process owner, a data steward, key linking technology and key actors are identified. We suggest service-oriented enterprise architecture and organising the units around the services they provide. These units should use a linking technology for integrating the different systems interacting in the process.

After defining this IT strategy, we need to communicate and share the vision. This is achieved by using SEAM and the tools SeamCAD and Solu-QIQ.

Using the Ph.D. hiring business process as an example, we describe the application of our proposed IT strategy. In several figures we show the SEAM as-is and to-be models. We illustrate a sample output of the Solu-QIQ tool and suggest steps to be taken for working on other processes.

From the overall work done so far, we conclude that the communication and the adoption of our approach is the most crucial part of the project. 


\section{Future Work}

We have presented how to optimize one business process within EPFL. But an overall IT strategy will be complete only if we address all core business processes. For the future work, we propose to iteratively follow the suggestions from Subsection 5.5 for the remaining processes.

In parallel, to ensure the QoS of the provided services, we must also focus on protecting EPFL from its environment. This mainly includes working on several security standards and protocols.

Finally, until now, we haven't done a validation of our approach, but we have the full support of EPFL's CIO to carry on with this project as a mean to have visibility and transparency on the services defined, the services' providers and the services' users. The validation will happen after the Solu-QIQ tool is used routinely and after we gather the first feedbacks from the people involved.

\section{References}

1. AB+Software. http://www.abplussoftware.fr/.

2. V. Anderson and L. Johnson. Systems thinking basics. Pegasus Communications, 1997.

3. C. Firth. Data quality in practice: experience from the frontline. In Conference of Information Quality, pages 25-26. John Wiley and Sons Inc., 1996.

4. M. Hammer and S. Stanton. How process enterprises really work. Harvard business review, 77:108-120, 1999.

5. Régie Autonome des Transports Parisiens. http://www.ratp.fr/.

6. J. W. Ross, P. Weill, and D. Robertson. Enterprise Architecture As Strategy: Creating a Foundation for Business Execution. Harvard Business Review Press, 2006.

7. I. Rychkova, G. Regev, L. Le, and A. Wegmann. From Business To IT with SEAM: the J2EE Pet Store Example. In Enterprise Distributed Object Computing Conference, 200\%. EDOC 200\%. 11th IEEE International, pages 495-495. IEEE, 2007.

8. SEAM Introduction. http://lams.epfl.ch/reference/seam/.

9. A. Wegmann. On the Systemic Enterprise Architecture Methodology (SEAM). In Published at the International Conference on Enterprise Information Systems 2003 (ICEIS 2003). Citeseer, 2003.

10. A. Wegmann, A. Kotsalainen, L. Matthey, G. Regev, and A. Giannattasio. Augmenting the Zachman Enterprise Architecture Framework With a Systemic Conceptualization. In Enterprise Distributed Object Computing Conference, 2008. EDOC'08. 12th International IEEE, pages 3-13. IEEE, 2008.

11. WSO2 Enterprise Service Bus. http://wso2.com/products/enterprise-service-bus/. 